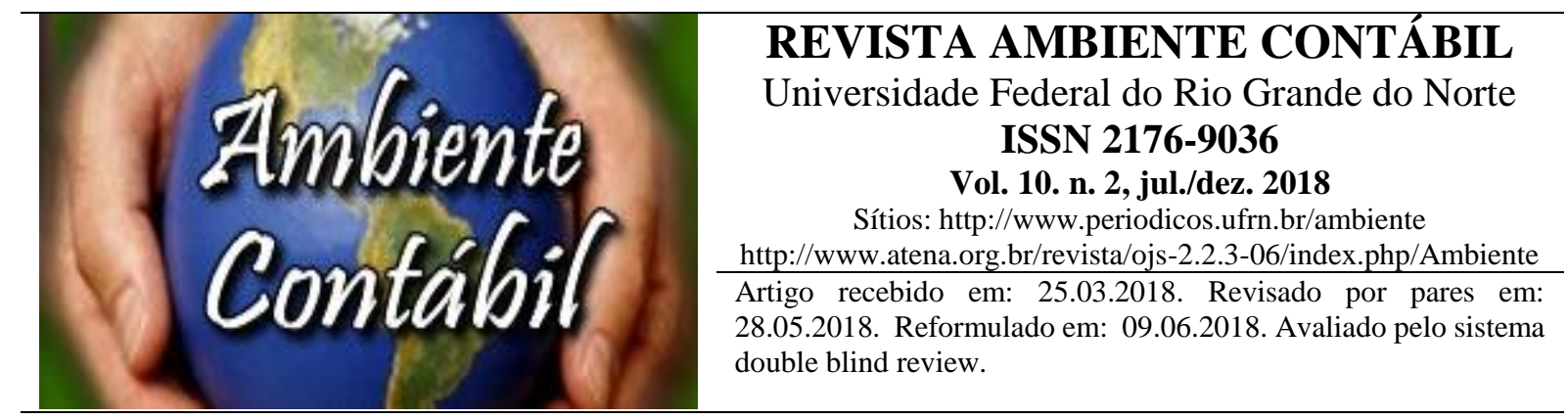

\title{
DETERMINANTES DA ESTRUTURA DE CAPITAL DE EMPRESAS BRASILEIRAS DE CAPITAL ABERTO EM PERÍODO DE CRISE
}

\section{DETERMINANTS OF THE CAPITAL STRUCTURE OF PUBLICLY TRADED COM- PANIES IN BRAZIL IN A PERIOD OF CRISIS}

\section{DETERMINANTES DE LA ESTRUCTURA DE CAPITAL DE EMPRESAS BRASILEÑAS DE CAPITAL ABIERTO EN PERÍODO DE CRISIS}

Autores:

\section{Paulo Augusto Pettenuzzo de Britto}

Professor Associado do Departamento de Ciências Contábeis e Atuariais e do Programa de Pós-Graduação em Ciências Contábeis da Universidade de Brasília. PhD em Economia pela University of Illinois. Endereço: Universidade de Brasília, Prédio da Faculdade de Economia, Administração, Contabilidade e Gestão de Políticas Públicas - FACE. Campus Universitário Darcy Ribeiro, Sala A1 16/7. Asa Norte; 70910900 - Brasília, DF - Brasil

Telefone: (61) 3107-0795 Identificadores (ID): ORCID: https://orcid.org/0000-0001-7462-9096 Lattes: http://lattes.cnpq.br/8801317938905787 E-mail: pbritto@unb.br

André Luiz Marques Serrano Professor Adjunto do Departamento de Administração e do Programa de Pós-Graduação em Ciências Contábeis da na Universidade de Brasília. Doutor em Economia pela Universidade de Brasília. Endereço: Universidade de Brasília, Prédio da Faculdade de Economia, Administração, Contabilidade e Gestão de Políticas Públicas - FACE. Campus Universitário Darcy Ribeiro, Sala B1 23/4. Asa Norte; 70910900 - Brasília, DF - Brasil

Telefone: (61) 3107-0885

Identificadores (ID):

ORCID: https://orcid.org/0000-0001-5182-0496 Currículo Lattes: http://lattes.cnpq.br/9297412598307091

E-mail: andrelms@unb.br

Víthor Rosa Franco Doutorando em Psicologia Social, do Trabalho e das Organizações na Universidade de Brasília. Mestre em Psicologia Social, do Trabalho e das Organizações (PPG-PSTO/UnB). Endereço: Instituto de Psicologia, Departamento de Psicologia Social e do Trabalho. 
Laboratório de Métodos e Técnicas de Avaliação - Campus Darcy Ribeiro ICC SUL, Sala A1- 61/4. Asa Norte; 70900-100 - Brasília, DF - Brasil

Telefone: (61) 3107-0885

Identificadores (ID):

ORCID: https://orcid.org/0000-0002-8929-3238

Currículo Lattes: http://lattes.cnpq.br/3561986383204396

E-mail: vithorfranco@gmail.com

\title{
RESUMO
}

O presente estudo tem por objetivo verificar empiricamente os fatores determinantes da estrutura de capital de empresas brasileiras de capital aberto, com ações negociadas na BM\&FBosvepa, no período 2010-2017. Os fatores considerados na análise são aqueles propostos nas principais teorias sobre estrutura de capital: rentabilidade, risco, tamanho, tangibilidade e oportunidades de crescimento. Subsidiariamente a estes fatores, incluiu-se um conjunto de dummies setoriais com o intuito de evidenciar eventual característica específica de dado setor. Para a análise empregou-se o método estatístico de dados em painel e modelos com efeitos fixos e com efeitos variáveis. A amostra foi composta por 186 empresas, dividias em 19 setores econômicos. Os testes estatísticos evidenciaram a não significância dos setores ao apontar pela estimação de um modelo com efeitos fixos. Os resultados indicam que rentabilidade, risco e oportunidades de crescimento induzem menor endividamento, que o tamanho de empresa induz maior endividamento e que a tangibilidade não teve influência sobre o nível de endividamento das empresas da amostra no período estudado. Em que pese apresentarem justificativas teóricas, os resultados obtidos, em conjunto, não permitem confirmar um teoria específica acerca da estrutura de capital de empresas de capital aberto.

Palavras-chaves: Estrutura de capital. Mercado Financeiro. Endividamento.

\begin{abstract}
This study aims to empirically verify the determinants of the capital structure of Brazilian publicly traded companies on the BM\&FBosvepa during 2010-2017. The factors considered in the analysis are those proposed in the main theories about capital structure: profitability, risk, size, tangibility and growth opportunities. Subsidiarily to these factors, a set of sectoral dummies was included in order to highlight any specific characteristic of a given economic sector. It was used the statistical method of panel data and models with fixed effects and with variable effects. The sample is composed of 186 companies, divided into 19 economic sectors. The statistical tests evidenced the non-significance of the sectors when pointing to the estimation of a model with fixed effects. The results indicate that profitability, risk and growth opportunities induce lower indebtedness, that company size induces greater indebtedness and that tangibility had no influence on the level of indebtedness of the companies of the sample in the studied period. In spite of their theoretical justification, the results obtained together do not confirm a specific theory about the capital structure of public companies.
\end{abstract}

Keywords: Capital structure. Financial Markets. Indebtedness.

\section{RESUMEN}

Esta investigación tiene como objetivo verificar empíricamente los determinantes de la estructura de capital de las empresas brasileñas de capital abierto con acciones en la BM\&FBosvepa, en el período 2010-2017. Los factores considerados en el análisis son aquellos propuestos en las principales teorías acerca de la estructura de capital: rentabilidad, riesgo, tamaño, tangibilidad y oportunidades de crecimiento. Subsidiariamente a estos factores, se incluyó un conjunto de indicadores sectoriales con el propósito de evidenciar eventual

Revista Ambiente Contábil - ISSN 2176-9036 - UFRN - Natal-RN. v. 10. n. 2, p. 364 - 383, jul./dez. 2018. 
característica específica de determinado sector económico. Para el análisis se empleó el método estadístico de datos en panel y modelos con efectos fijos y con efectos variables. La muestra fue compuesta por 186 empresas, divididas en 19 sectores. Las pruebas estadísticas evidenciaron no significancia de los sectores al apuntar por la estimación de un modelo con efectos fijos. Los resultados indican que la rentabilidad, el riesgo y las oportunidades de crecimiento inducen un menor endeudamiento, que el tamaño de empresa induce mayor endeudamiento y que la tangibilidad no tuvo influencia sobre el nivel de endeudamiento de las empresas de la muestra en el período estudiado. En los que pesan presentar justificación teórica, los resultados obtenidos, en conjunto, no permiten confirmar una teoría específica sobre la estructura de capital das empresas.

Palavras-chaves: Estructura de capital. Mercado de Financeiro. Endividamento.

\section{INTRODUÇÃO}

Diante da complexidade do funcionamento do mercado financeiro nas economias modernas, as empresas se veem em constantes necessidades de investimentos em novos produtos, na abertura de novos mercados e na inserção de novas tecnologias. Para tanto, as empresas devem buscar financiamento, seja lançando mão de recursos próprios, seja na forma de capital de terceiros. A moderna teoria das finanças corporativas trata desta questão desde o seminal trabalho de Modigliani e Miller (1958), que abordou a questão da relação entre estrutura de capital o valor da empresa. Desde então, uma questão mais específica foi formulada, objetivando determinar uma regra para determinação da estrutura de capital ótima, aquela que maximiza o valor da empresa.

A literatura referente a esse campo teórico tem, portanto, o trabalho de Modigliani e Miller (1958) como a pesquisa pioneira. Em seu estudo, os autores sugerem que a maneira como as empresas se financiam não influencia seus valores. Destaque-se, contudo, que aquela análise foi feita sob um conjunto de hipóteses simplificadoras que, mais tarde, comprovaram-se como determinantes para o resultado. Como consequência, uma extensa literatura acerca da estrutura de capital se desenvolveu, afastando-se da questão da determinação de uma estrutura ótima de capital, para a análise de fatores individuais que em tese seriam determinantes do nível médio de endividamento de empresas inseridas em diferentes mercados e em distintos momentos no tempo.

Dentre os principais estudos frequentemente consultados podem-se destacar, além do pioneiro Modigliani e Miller (1958), os trabalhos de Modigliani e Miller (1963), Baxter (1967), Jensen e Meckling (1976), Ross (1977), DeAngelo e Masulis (1980), Myers (1984), Myers e Majluf (1984), Narayanan (1988), Baskin (1989), Heinkel e Zechner (1990) e Rajan e Zingales (1995). Tais trabalhos consideram suposições distintas acerca da forma de taxação do capital e dos lucros, da presença de custos por insolvência e de custos de agência e sobre o uso de informação por agentes de mercado. Em resumo, supõe níveis distintos de eficiência de mercado. Verifica-se, por meio de evidências empíricas apresentadas por estes e diversos outros estudos que os ditos fatores explicam a estrutura de capital das empresas.

A maneira com que uma empresa escolhe sua estrutura de capital ainda é, portanto, um assunto controverso na área de finanças corporativas. As pesquisas desenvolvidas não tiveram resultados suficientes para determinar como uma empresa deve escolher e como se dará o financiamento de seus investimentos, se preferencialmente por dívida ou por capital próprio, confirmando ou não uma dada hipótese teórica. Com efeito, pode-se afirmar que a pesquisa sobre o tema é, assim, eminentemente empírica, orientada para se evidenciar como empresas buscam financiamento em dada jurisdição, em dado momento no tempo. Adicionalmente, ao evidenciar tal comportamento médio de mercado, pode-se tentar explica-lo com base em fatos, ou choques, ocorrido naquele mercado. Essa questão levou ao desenvolvimento de várias

Revista Ambiente Contábil - ISSN 2176-9036 - UFRN - Natal-RN. v. 10. n. 2, p. 364 - 383, jul./dez. 2018. 
proposições que buscavam estabelecer quais seriam os determinantes da estrutura de capital de empresas (PEROBELLI; FAMÁ, 2002).

Segundo Nakamura e Martin (2007), a busca por determinantes do nível de endividamento tem implícita a ideia da otimização da estrutura de capital. Estes autores defendem que, partindo do pressuposto da existência desse nível ótimo de endividamento, é interessante identificar que fatores o determinam, para atender principalmente a dois objetivos: analisar empiricamente a validade das teorias sobre estrutura de capital e proporcionar aos administradores indicações claras sobre quais fatores devem ser levados em consideração na decisão da estrutura de capital da entidade.

Em que pese a extensa literatura sobre o tema, não há consenso sobre os fatores que determinam o nível de endividamento das empresas. Estudos empíricos acerca de um conjunto de variáveis teoricamente bem justificadas têm demonstrado inconsistências em seus resultados. Uma hipótese para tanto é a de que alguns fatores são mais relevantes que outros para a tomada de decisões em conjunturas econômicas distintas. Neste contexto, o estudo aborda a questão da estrutura de capital sob a ótica de suas determinantes, conforme a prescrição teórica e evidências empíricas existentes, a partir de informações de empresas brasileiras de capital aberto num período de crise. Subsidiariamente ao fato de abordar a problemática no período de ajuste, o estudo investiga se setores específicos da atividade econômica podem ser caracterizados por estrutura de capital distinta.

Por fim, justifica-se o estudo pela relevância do tema, caracterizada pelo número de hipóteses teóricas, modelos concorrentes e estudos empíricos realizados ao longo das últimas cinco décadas, jamais deixando de ser um tema de interesse tanto de acadêmicos, como de práticos. Constituindo uma peça nessa literatura, este estudo pode contribuir para uma futura meta análise que busque identificar não os fatores determinantes de estrutura de capital, mas quais daqueles fatores são determinantes em dado contexto macroeconômico.

O trabalho está estruturado em cinco seções, além desta introdução. A próxima referese à revisão de tópicos específicos de finanças com vistas à compreensão da estrutura de capital. A terceira traz a metodologia adotada e da descrição dos dados. A quarta apresenta os resultados obtidos e as discussões pertinentes. Por fim, a quinta seção conclui o artigo.

\section{REFERENCIAL TEÓRICO}

\subsection{AS TEORIAS SOBRE ESTRUTURA DE CAPITAL}

O trabalho revolucionário de Modigliani e Miller (1958) relata a irrelevância da maneira com que as empresas se financiam. Para eles, dois bens iguais devem ser avaliados pelo mesmo valor, independentemente da maneira com que são financiados. Portanto, o valor da empresa estaria associado somente à sua rentabilidade e seu risco, e não ao instrumento utilizado para seu financiamento. Logo, o nível de endividamento de uma empresa dependeria simplesmente das preferências de gestores e de proprietários. Cabe ressaltar que o resultado obtido tinha relação estreita com as suposições do modelo, quais sejam preços de mercado fixados conforme um passeio aleatório, ausência de impostos, ausência de custos de insolvência, custos de agência negligenciáveis, informação perfeita, mercados eficientes, e agentes racionais.

Após a provocação de Modigliani-Miller (MM), as pesquisas sobre estrutura ótima de capital estudavam os efeitos de relaxamento das hipóteses restritivas do modelo MM original. Exemplos disso são Modigliani-Miller (1963), que introduz impostos, Jensen e Meckling (1976), que introduz custo de agência, Miller (1977), que considera custos de tributação e de falência, e Myers e Majluf (1984), que introduz assimetria de informação. 
A Teoria da Agência, enunciada por Jensen e Meckling (1976), pressupõe relacionamento entre um principal e um agente, que é contratado pelo primeiro para a execução de uma tarefa. Assumindo-se preferências distintas entre principal e agente, evidencia-se um potencial conflito de interesses: as ações dos agentes não necessariamente vão atender ao desejo do principal. Esse efeito é o chamado custo de agência.

Aplicada à análise da estrutura de capital, a Teoria da Agência considera tanto o conflito de interesses de gerentes e de acionistas, como o conflito de interesses de credores e de acionistas. O primeiro deve-se ao fluxo de caixa livre da empresa, após o financiamento dos projetos com valor presente líquido positivo. Esse caixa seria utilizado para investimentos menos lucrativos, como escritórios luxuosos ou viagens de primeira classe. Para amenizar esse conflito, uma solução seria aumentar a participação acionária dos administradores. Outra solução seria utilizar mais capital de terceiros, pois isso compromete parte do caixa livre da empresa com o pagamento de juros, evitando investimentos desnecessários (Machado et al., 2015).

Já o conflito de interesses de credores e de acionistas faz com que uns altos níveis de endividamento incentivem os acionistas a investirem em projetos mais arriscados, com lucros esperados mais elevados. Isso porque se o projeto for rentável, a maior parte do lucro ficará com os acionistas, afinal a remuneração paga aos credores é fixa. No caso de fracasso do projeto, a empresa poderá falir e os credores perderão seus investimentos. No entanto, aos credores é necessário antecipar tal comportamento dos acionistas e cobrar mais caro de empresas muito endividadas. Logo, dados os conflitos explicados, a teoria de agência determina que o ponto ótimo de endividamento seja aquele que minimiza o custo de agência total, maximizando o valor da empresa (ISLAM; KHANDAKER, 2015).

Outra teoria relevante refere-se à Static Trade-off, desenvolvida por Miller (1977), que defende que a estrutura de capital ótima da empresa seria aquela que considera o efeito do benefício fiscal gerado pelo endividamento e o efeito dos custos de falência, de maneira que exista um meio termo onde o custo de capital seja mínimo. Ao se considerar o efeito dos impostos (dedutibilidade dos juros pagos), se a taxa de juros efetiva se mantiver abaixo do custo do capital próprio, o valor da empresa cresce à medida que ela se endivida, pois com o benefício fiscal, seu custo de capital cai. Sob essa ótica, a empresa deveria se financiar totalmente por capital de terceiros.

Entretanto, os credores impõem limites ao endividamento, afinal, quanto mais endividada é a empresa, maior é o risco do credor, o que torna o custo da dívida crescente com o endividamento. Isso, somado à necessidade de uma reserva para captar dívidas em caso de emergência, torna improvável que alguma empresa se financie completamente com capital de terceiros, a despeito do efeito dos impostos sobre o custo de capital total. Posteriormente, os custos de falência passaram a ser considerados como possíveis responsáveis por mudanças no custo de capital de uma empresa. Deste modo, o custo de capital não seria sempre decrescente à medida que a empresa se endivida, mas teria forma de $\mathrm{U}$, mostrando que o endividamento traz benefício até certo ponto, e que, após esse limite, ele passa a comprometer a saúde financeira da companhia (PEROBELLI; FAMÁ, 2002).

Outra teoria sobre estrutura de capital refere-se a informações assimétricas, no qual os administradores assumem que possuem informações que os investidores não têm e vice-versa. Essa teoria, introduzida por Ross (1977), e posteriormente discutida por Brealey, Leland e Pyle (1977), postula que os administradores conheçam a distribuição dos resultados futuros esperados da empresa, ao passo que os investidores, sejam eles credores ou acionistas, não. Assim, aos assumir dívidas a empresa estaria sinalizando para o investidor a expectativa de fluxos de caixa positivos no futuro. Portanto, os investidores enxergam o endividamento como sinal de qualidade na empresa (MORAES, 2005). 
Também assumindo a presença de assimetria de informação destaca-se a teoria do Pecking Order, desenvolvida por Myers e Majluf (1984). De acordo com a Pecking Order, haveria uma hierarquia na decisão de financiamento das empresas. Como os investidores não têm total conhecimento das informações sobre a empresa, eles tendem a precificar suas ações por um preço médio. Isso acaba subavaliando as ações de boas companhias e superavaliado as das ruins. Portanto, com as novas ações subavaliadas, a emissão de novas ações penaliza os acionistas antigos, premiando os novos (MORAES, 2005).

Assim, para evitar esse problema, uma solução seria utilizar recursos gerados internamente (o autofinanciamento), pois esses recursos não serão subavaliados. Caso isso não seja possível, uma segunda opção seria a contração de dívidas, pois esse recurso também não seria subavaliado. Esgotadas essas possibilidades, aí sim a empresa teria que emitir novas ações para viabilizar o projeto (FERREIRA; BRASIL, 1997). Com efeito, a capacidade de gerar lucro da empresa deveria influenciar sua estrutura de capital, de maneira que empresas com maior potencial de autofinanciamento deverão recorrer menos à contração de dívidas. Portanto, deve haver uma relação negativa entre a rentabilidade da empresa e seu endividamento (CRISTÓFALO et al., 2016).

Ainda sob assimetria de informação, Myers (1984) desenvolveu a teoria conhecida como Static Trade-off, um modelo que tem por objetivo promover o equilíbrio entre o risco de falência associado às dívidas e as vantagens fiscais do endividamento (ANDERSEN, 2005). A teoria estabelece que quanto maior for à volatilidade do valor da empresa, maior será é a probabilidade de insolvência insolvente, portanto, o risco e o endividamento estão inversamente relacionados. Pela associação de risco e retorno, a teoria sugere também que a rentabilidade e o endividamento tenham relação negativa. Logo, quanto maior o risco a que a empresa for submetida, maiores serão as dificuldades da empresa de manter fluxo de caixa capaz de honrar seus compromissos, além de as taxas de retorno exigidas para a contração de dívidas serem maiores, desestimulando o financiamento por capital de terceiros. Portanto, essas deverão se endividar menos.

Ainda segundo a Static Trade-off, grandes empresas tendem a apresentar maior diversificação de seus negócios, diminuindo sua probabilidade de falência. Ao mesmo tempo, as grandes empresas têm acesso maior a crédito, além de taxas mais baixas. Portanto, a hipótese adotada é de que o tamanho da empresa e seu endividamento tenham relação positiva. Ademais, a teoria estabelece que empresas com maior proporção de ativos fixos têm menor custo de falência, em razão de esses ativos poderem ser vendidos em caso de liquidação.

Além disso, segundo a teoria dos custos dos agentes, os ativos tangíveis servem de proteção aos credores contra estratégias arriscadas dos acionistas, de maneira que, em caso de liquidação, os ativos funcionam como garantia. Os credores, portanto, devem emprestar a um custo mais baixo para empresas com alta tangibilidade de ativos, enquanto empresas com baixa proporção de ativos fixos devem ter mais dificuldade de acesso a crédito. Vale salientar que a estrutura de capital de uma empresa diz respeito à participação de diferentes fontes de recursos no financiamento de seus ativos, existem basicamente duas fontes de financiamento: capital próprio, que corresponde ao patrimônio líquido da entidade, e, no caso das companhias abertas, o montante financiado por emissão de ações; e capital de terceiros, que corresponde aos passivos exigíveis de curto ou de longo prazo. Desta forma, empresas podem optar pela estrutura de capital que desejarem, priorizando capital próprio ou de terceiros. Porém, para fazer essa escolha, a entidade deve considerar sua avaliação pela relação risco-retorno, e então decidir qual é a proporção entre capital próprio e endividamento que melhor atende ao seu objetivo de maximizar a riqueza dos acionistas (MACHADO et al., 2015).

Ao optar pelo financiamento por capital de terceiros, a empresa ganha em rentabilidade, pois a remuneração paga aos credores (juros) geralmente é inferior ao custo de capital próprio, tornando possível que ela se aproprie do spread entre o retorno de seus investimentos e o custo

Revista Ambiente Contábil - ISSN 2176-9036 - UFRN - Natal-RN. v. 10. n. 2, p. 364 - 383, jul./dez. 2018. 
efetivo de sua dívida. Sendo assim, Favato (2007) afirmou que a agregação de dívidas ao capital próprio constitui um mecanismo de alavancagem, capaz de aumentar a lucratividade obtida pelos acionistas, bem como o risco associado a esta.

Por outro lado, as empresas podem reduzir seu risco optando pelo financiamento por capital próprio. Ao fazê-lo, ela se exime da obrigação de pagamento aos credores em prazo determinado, reduzindo a chance de falência. Contudo, isso torna o capital próprio mais caro que o capital de terceiros, o que diminui a rentabilidade da empresa. A escolha, portanto, está relacionada ao custo de capital total da empresa. A estrutura de capital recomendada é aquela que gera o menor custo de capital total e, dada uma taxa de retorno dos investimentos, maximiza $\mathrm{o}$ a riqueza dos acionistas. Porém, existem divergências na teoria de finanças quanto à existência ou não dessa estrutura de capital ótima (FAMÁ; GRAVA, 2000).

Outro fator associado à estrutura de capital sob assimetria de informação é o nível de tangibilidade dos ativos da empresa. Neste caso, sendo o nível de tangibilidade dos ativos de uma empresa observável pelos credores, tal indicador deveria ser analisado quando de suas decisões de investimento. Assim, ao emprestar para empresas com mais ativos fixos, os credores teriam alguma garantia de recebimento em caso de falência. Dessa forma, quanto maior for a proporção de ativos fixos da empresa, maior deve ser seu endividamento.

Quando se trata sobre a relação entre endividamento e oportunidades de crescimento, as duas teorias divergem. Conforme o Static Trade-off, uma empresa com grandes oportunidades de crescimento tem seu valor determinado por grande expectativa de retorno futuro, além de uma grande quantidade de ativos intangíveis, que não têm valor em caso de liquidação. Portanto, essas empresas têm alto custo de falência, o que faz com que elas mantenham um baixo endividamento, além de fazer com que o capital de terceiros fique mais caro (GOMES; LEAL, 2000). Com efeito, a teoria postula que endividamento e oportunidades de crescimento sejam negativamente relacionados. Já a Pecking Order postula relação inversa devido à incapacidade de autofinanciamento. Em situações de altas oportunidades de crescimento empresas que necessitassem de altos investimentos não seriam capazes de se autofinanciar, tendo de recorrer ao capital de terceiros.

Considerando-se as duas teorias mais completas - em termos de relaxamento de suposições restritivas do modelo MM - apresenta-se o Quadro 1, contendo um comparativo das suas respectivas previsões teóricas.

\section{Quadro 1: Relações teóricas entre endividamento e fatores relevantes postuladas pelas} teorias do Pecking Order e do Trade-off.

\begin{tabular}{|l|l|l|}
\hline Determinantes & Pecking Order & Trade-Off \\
\hline Rentabilidade & Negativa & Positiva \\
\hline Risco & Negativa & Negativa \\
\hline Tamanho & Não prevista & Positiva \\
\hline Tangibilidade dos ativos & Negativa & Negativa \\
\hline Oportunidades de Crescimento & Positiva & Pa \\
\hline
\end{tabular}

Fonte: Elaborado pelos autores.

\subsection{ESTUDOS EMPÍRICOS ACERCA DA ESTRUTURA DE CAPITAL DE EMPRESAS NO BRASIL}

Desta forma, vale destacar que o presente estudo foi baseado em diversas pesquisas realizadas no Brasil. No quadro abaixo estão listados os principais estudos realizados, assim como as variáveis independentes mais comumente observadas em cada pesquisa: rentabilidade, risco, tangibilidade de ativos e oportunidades de crescimento. São mostradas as relações estatisticamente significantes encontradas para cada variável independente. 
Quadro 2: Fatores relacionados à estrutura de capital analisados em pesquisas anteriores no Brasil, com sinal do impacto marginal, pesquisas selecionadas, 1999-2016.

\begin{tabular}{|l|c|c|c|c|c|}
\hline \multicolumn{1}{|c|}{ Pesquisa } & Rentabilidade & Risco & Tamanho & Tangibilidade & Crescimento \\
\hline Gomes (1999) & - & - & + & + & - \\
\hline Gomes e Leal (2000) & - & n.s. & + & + & - \\
\hline Perobelli e Famá (2002) & - & n.s. & - & n.s. & - \\
\hline Moraes (2005) & - & n.s. & + & n.a. & n.s. \\
\hline Brito et al (2007) & n.s. & + & + & - & + \\
\hline Favato (2007) & - & - & + & - & - \\
\hline Nakamura et al. $(2007)$ & - & - & - & n.a. & - \\
\hline Favato e Rogers (2008) & - & - & + & - & - \\
\hline Kirch (2008) & - & n.s. & n.s. & + & - \\
\hline Bastos e Nakamura (2009) & - & + & - & - & + \\
\hline Pohlman e Iudícibus (2010) & - & n.s. & + & n.s. & n.s. \\
\hline Angonese et al. $(2011)$ & n.s. & n.a. & + & n.a. & n.a. \\
\hline Albanez et al. $(2012)$ & - & - & n.s. & + & n.s. \\
\hline Gonçalves et al. $(2012)$ & n.s. & - & n.s. & n.s. & - \\
\hline Correa et al. (2013) & - & + & n.s. & - & n.s. \\
\hline Martins e Terra (2014) & - & n.a. & + & + & - \\
\hline Locatelli et al. $(2015)$ & - & n.s. & - & n.a. & n.a. \\
\hline Brunozi et al. $(2016)$ & - & n.a. & + & n.s. & - \\
\hline
\end{tabular}

n.s.: relação analisada, com resultado não significante; n.a.: relação não analisada.

Fonte: Elaborado pelos autores.

Além dos determinantes da estrutura de capital listados no Quadro 2, Bastos e Nakamura (2009) testaram o pagamento de imposto de renda (insignificante) e o market to book value (relação positiva) como possíveis determinantes. Favato (2007) fez um estudo utilizando empresas de capital aberto e de capital fechado, portanto, utilizou o tipo de capital como variável independente. Kirch (2008) estudou o efeito da estrutura de controle no endividamento, mas não encontrou significância estatística.

Nakamura et al. (2007) pesquisaram também o efeito da economia fiscal e da taxa de crescimento das vendas na estrutura de capital de empresas, obtendo significância apenas para o segundo (relação negativa). A liquidez corrente também foi alvo da pesquisa de Nakamura et al. (2007) e Bastos e Nakamura (2009), e foi encontrada relação negativa com o endividamento.

Já Moraes (2005) utilizou como possíveis determinantes da estrutura de capital a concentração do setor, o poder de barganha dos empregados, a reputação da empresa e a integração vertical, encontrando relação positiva para os três primeiros. A integração vertical não se mostrou estatisticamente significante.

Perobelli e Famá (2002) investigaram os efeitos da singularidade e de outros benefícios fiscais não gerados pelo endividamento sobre a alavancagem financeira da entidade, mas não encontraram significância estatística.

Outras variáveis, tais como o tipo de controle, a tributação, o grupo empresarial e a ações em bolsa foram possíveis determinantes apontados no estudo de Pohlman e Iudícibus (2010). Destes, apenas a tributação encontrou significância estatística, com relação positiva. Brito et al. (2006) também utilizaram o tipo de controle da empresa em sua pesquisa, sem encontrar relação significante. 


\section{METODOLOGIA}

A análise dos determinantes da estrutura de capital foi feita a partir de uma base de dados em painel, tendo em vista a análise cross-section em uma série temporal. Os dados utilizados foram extraídos do software Economática Pro Database. O período escolhido para análise compreende os anos de 2010 a 2017, totalizando, portanto, oito anos. Essa escolha se deu para amenizar os efeitos da crise mundial ocorrida em 2008, porém ainda conseguindo cobrir um período razoável. Acrescente-se que o período considerado, com se sem overlap com os períodos objeto dos estudos sumarizados no Quadro 2 permite exatamente comparar os resultados haja vista, conforme discussão anterior, não haver uma teoria confirmada sobre estrutura ótima de capital.

Foram realizadas regressões utilizando modelos com efeitos fixos e com efeitos aleatórios. No modelo com efeitos aleatórios, as variáveis de cada empresa ao longo do tempo são tratadas como variáveis aleatórias, como se cada empresa em cada ano fosse uma empresa diferente. Já em modelos com efeitos fixos, é calculado um intercepto diferente para cada indivíduo, ou seja, é considerada a variação de cada empresa no tempo.

As empresas utilizadas na amostra foram as de capital aberto, com ações negociadas na Bolsa de Valores, Mercadorias e Futuros de São Paulo (BM\&FBOVESPA) para o período analisado. A amostra restou composta por 186 empresas, divididas em 19 setores industriais, classificados pela própria base de dados da Economática. $\mathrm{O}$ quadro a baixo mostra o número de empresas por setor industrial.

Quadro 3: Empresas da amostra, conforme classificação por setores industriais.

\begin{tabular}{|c|l|c|}
\hline Código & Descrição das Empresas & Quantidade de Empresas \\
\hline 1 & Agro e Pesca & 1 \\
\hline 2 & Alimentos e Bebidas & 10 \\
\hline 3 & Comércio & 12 \\
\hline 4 & Construção Civil & 18 \\
\hline 5 & Eletroeletrônicos & 4 \\
\hline 6 & Energia Elétrica & 20 \\
\hline 7 & Minerais não Metálicos & 1 \\
\hline 8 & Mineração & 3 \\
\hline 9 & Máquinas Industriais & 4 \\
\hline 10 & Papel e Celulose & 4 \\
\hline 11 & Petróleo e Gás & 2 \\
\hline 12 & Química & 9 \\
\hline 13 & Siderúrgica e Metalúrgica & 13 \\
\hline 14 & Telecomunicações & 5 \\
\hline 15 & Têxtil & 14 \\
\hline 16 & Transporte Serviço & 9 \\
\hline 17 & Veículos e Peças & 11 \\
\hline 18 & Outros & 45 \\
\hline 19 & Software e Dados & 1 \\
\hline & & 186 \\
\hline
\end{tabular}

Fonte: Elaborado pelos autores.

Para conseguir comprovação quantitativa do apontado pelas teorias, no que diz respeito aos determinantes da estrutura de capital, toda pesquisa se depara com a dificuldade de que aqueles atributos constituem conceitos abstratos e, portanto, não são facilmente observados. Com efeito, faz-se necessário o uso de proxys para os indicadores não observáveis (PEROBELLI; FAMÁ, 2002). 
Entretanto, existem problemas associados a essa metodologia. Há dificuldade na escolha dessas proxys, pois não é simples encontrar medidas que estejam relacionadas apenas a um atributo, fazendo com que a medida reflita também o efeito de outros atributos. Além disso, pode inclusive existir mais de uma proxy utilizada para medir o mesmo atributo, tornando a escolha ainda mais complicada. Portanto, assim como Gomes e Leal (2000), a escolha das variáveis teóricas foi feita conforme três critérios: suporte da teoria, utilização em pesquisas anteriores e a disponibilidade de dados.

Assim, como fizeram Kirch (2005) e Gomes e Leal (2000), foram utilizadas duas proxys para o endividamento como variáveis dependentes. A primeira delas é o endividamento contábil (EndCont), calculado como a soma das dívidas de curto e longo prazo, ou seja, passivo circulante e exigível a longo prazo $(P C+E L P)$, dividido pelo ativo total $(A T)$. Já a dívida a valor de mercado (EndMer) é a razão entre as dívidas totais e a soma das dívidas totais com o valor de mercado do patrimônio líquido $(V M)$, sendo este calculado mediante a multiplicação da quantidade de ações pelo preço unitário do último dia útil do ano corrente. As fórmulas abaixo resumem as variáveis dependentes.

$$
\begin{gathered}
\text { EndCont }=\frac{P C+E L P}{A T} \\
\text { EndMer }=\frac{P C+E L P}{P C+E L P+V M}
\end{gathered}
$$

Com respeito às variáveis independentes, foram selecionadas métricas para rentabilidade, risco, tamanho, tangibilidade e perspectivas de crescimento. A rentabilidade (Rent) é obtida pela razão entre o lucro operacional antes de juros, impostos, depreciação e amortização (EBITDA) e o ativo total ( $A T)$, conforme a fórmula (3).

$$
\text { Rent }=\frac{E B I T D A}{A T}
$$

Apesar de Gomes e Leal (2000) sugerirem "imaginar outras medidas de risco que possam ser utilizadas nos testes", a proxy mais utilizada em pesquisas semelhantes para quantificar o riso é o desvio padrão da rentabilidade.

Como medida indicador de risco optou-se por utilizar como proxy o desvio padrão da rentabilidade, calculada conforme a fórmula acima, dos três anos anteriores ao ano corrente. Essa proxy, também utilizada por Moraes (2005), é representada pela equação (4).

$$
\text { Risco }=\left[\frac{1}{2} \sum_{i=t}^{t-2}\left(\operatorname{Rent}_{i-1}-\overline{\operatorname{Rent}}\right)\right]^{1 / 2}
$$

Alguns estudos utilizaram o ativo total para quantificar o tamanho da empresa (Tam). Neste estudo optou-se pelo logaritmo natural da receita líquida $(R L)$ como medida de tamanho, conforme a equação (5), pois a receita revela mais sobre a capacidade de pagamento da empresa, além de ser a proxy mais utilizada em estudos anteriores.

$$
\operatorname{Tam}=\ln (R L)
$$

Assim como em Bastos e Nakamura (2009), a proxy utilizada para a tangibilidade dos ativos (Tang) é a razão entre a soma do ativo imobilizado (Imob) e os estoques (Est) com e o ativo total $(A T)$, conforme (6).

Revista Ambiente Contábil - ISSN 2176-9036 - UFRN - Natal-RN. v. 10. n. 2, p. 364 - 383, jul./dez. 2018. 


$$
T a n g=\frac{I m o b+E s t}{A T}
$$

As oportunidades de crescimento ( $O p C r e s)$ são medidas como a razão entre o ativo total $(A T)$ menos o patrimônio líquido $(P L)$ mais o valor de mercado $(V M)$, com o ativo total, conforme (7), da mesma maneira que fizeram Gomes e Leal (2000) e Kirch (2005).

$$
\text { opCres }=\frac{A T-P L+V M}{A T}
$$

Por fim, com respeito às dummies para os setores, destaque-se que para algumas categorias o número de ocorrências é pequeno. Tal fato pode retornar coeficientes não significativos devido ao valor da variância. Para contornar a priori esse problema as alternativas, considerando a impossibilidade de aumentar a amostra, seriam ou desconsiderar as dummies, ou combinar categorias. Optou-se, contudo, por não fazer ajuste, mas deixar que as estimações respondam a esta situação.

Com respeito aos modelos estatísticos, foram estimados dois, um para cada variável dependente definida acima, endividamento contábil [equação (8)] e endividamento a valor de mercado [equação (9)]. As variáveis explicativas foram as mesmas em ambas as estimações. Para os dois modelos foram realizadas regressões com efeitos fixos e com efeitos aleatórios.

$$
\begin{aligned}
\text { EndCont }_{i, t} & =\beta_{0}+\beta_{1} \text { Rent }_{i, t}+\beta_{2} \text { Risco }_{i, t}+\beta_{3} \operatorname{Tam}_{i, t}+\beta_{4} \text { Tang }_{i, t}+ \\
& +\beta_{5} \text { OpCres }_{i, t}+\beta_{5+k} \sum_{k=1}^{18} \text { Setor }_{i, t}^{k}+\varepsilon_{i, t} \\
\text { EndMer }_{i, t} & =\beta_{0}+\beta_{1} \text { Rent }_{i, t}+\beta_{2} \text { Risco }_{i, t}+\beta_{3} \operatorname{Tam}_{i, t}+\beta_{4} \text { Tang }_{i, t}+ \\
& +\beta_{5} \text { OpCres }_{i, t}+\beta_{5+k} \sum_{k=1}^{18} \text { Setor }_{i, t}^{k}+u_{i, t}
\end{aligned}
$$

em que $i$ designa a empresa, $t$ o ano e $\varepsilon$ e u designam os erros aleatórios com média zero e variância constante.

Por fim, destaque-se que os coeficientes serão estimados por mínimos quadrados ordinário, com os resultados sujeitos aos testes de diagnósticos dos resíduos para validação das hipóteses de homocedasticidade e não autocorrelação serial, além da implementação dos teste de Hausman para escolha do modelo com entre aqueles com efeitos fixos ou variáveis. A multicolinearidade será verificada através da análise da matriz de correlações. 


\section{RESULTADOS: ANÁLISE E DISCUSSÕES}

Na tabela 1 estão listadas as estatísticas descritivas para cada uma das variáveis, tanto as dependentes como as independentes.

Tabela 1: Estatísticas Descritivas

\begin{tabular}{lccccccc}
\hline & EndCont & EndMer & Rent & Risco & Tamanho & Tang & OpCresc \\
\hline Mínimo & 0,0179 & 0,0168 & 1,2832 & 0,0012 & 7,1730 & 0,0002 & 0,5521 \\
$1^{\circ}$ Quartil & 0,4633 & 0,4120 & 0,0612 & 0,0163 & 13,122 & 0,1778 & 0,9713 \\
Mediana & 0,5948 & 0,5432 & 0,0899 & 0,0401 & 14,3782 & 0,3897 & 1,1784 \\
Média & 0,6340 & 0,5234 & 0,0944 & 0,0567 & 14,2843 & 0,3428 & 1,4572 \\
$3^{\circ}$ Quartil & 0,7523 & 0,6478 & 0,1482 & 0,0445 & 14,2356 & 0,6056 & 1,2340 \\
Máximo & 4,1261 & 0,9904 & 0,5652 & 0,9980 & 18,9950 & 0,9337 & 8,6330 \\
Variância & 0,0873 & 0,0600 & 0,0135 & 0,0981 & 2,2989 & 0,2014 & 0,8702 \\
Desvio Padrão & 0,3448 & 0,2398 & 0,1281 & 0,1127 & 1,5890 & 0,2290 & 0,9481 \\
\hline
\end{tabular}

Fonte: Dados da pesquisa.

A tabela 2 apresenta a matriz de correlações. Percebe-se que as correlações das variáveis dependentes com cada uma das variáveis independentes estão próximas, porém sugerindo que o endividamento contábil seja mais bem explicado pelo risco e que o endividamento contábil seja mais bem explicado pelas oportunidades de crescimento. A maior correlação encontrada é a entre a variável EndMer e a variável OpCres, de -0,553, o que indica que 53,3\% das variações da variável OpCres são seguidas, em sentido contrário, pela variável EndMer. Percebe-se também que não há correlação alta entre as variáveis independentes (a maior delas é a correlação entre a rentabilidade e as oportunidades de crescimento, que é de 0,362 ), sugerindo, portanto, não haverá problemas de multicolinearidade.

Tabela 2: Matriz de Correlações

\begin{tabular}{lrrrrrrr}
\hline & EndCont & EndMer & Rent & Risco & Tamanho & Tang & OpCresc \\
\hline EndCont & 1,0000 & & & & & & \\
EndMer & 0,6580 & 1,0000 & & & & & \\
Rent & $-0,4489$ & $-0,4387$ & 1,0000 & & & & \\
Risco & 0,2854 & 0,0152 & $-0,1857$ & 1,0000 & & & \\
Tamanho & $-0,0478$ & $-0,0776$ & 0,2407 & $-0,1754$ & 1,0000 & & \\
Tang & 0,1325 & 0,0791 & $-0,0857$ & 0,1065 & 0,1234 & 1,0000 & \\
OpCresc & 0,0895 & $-0,5531$ & 0,3626 & 0,1109 & 0,1145 & $-0,0500$ & 1,0000 \\
\hline
\end{tabular}

Fonte: Dados da pesquisa.

Com respeito aos teste de diagnóstico, foram realizadas as análises padrão para heterocedasticidade, o teste de Breush-Pagan, e para autocorrelação, o teste de Durbin-Watson. Foi realizado, ainda, o teste de Hausman para subsidiar a escolha entre o modelo com efeitos fixos ou efeitos aleatórios. Os resultados dos três testes são apresentados na Tabela 3. 
Tabela 3: Testes de diagnóstico

\begin{tabular}{c|c|c}
\hline \multicolumn{3}{c}{ Breush-Pagan } \\
\hline Variável Dependente & Estatística do Teste (BP) & $p$-valor \\
\hline EndCont & 93,6213 & $1,26 \mathrm{E}-10$ \\
\hline EndMer & 124,798 \\
\hline Vuriável Dependente & Estatística do Teste (DW) & $p$-valor \\
\hline EndCont & 2,0918 & 0,8849 \\
\hline EndMer & 2,0689 & 0,8687 \\
\hline Variável Dependente & & $p$-valor \\
\hline EndCont & Estatística do Teste $\left(x^{2}\right)$ & $2,19 \mathrm{E}-16$ \\
\hline EndMer & 104,1831 & 0,0019 \\
\hline
\end{tabular}

Fonte: Dados da pesquisa.

O teste de Breush-Pagan indicou a rejeição da hipótese de homocedasticidade. Com o intuito de corrigir esse problema, todas as regressões foram rodadas utilizando o método White Cross-Section de covariância do coeficiente. O teste de Durbin-Watson não rejeitou a hipótese de não autocorrelação entre os resíduos.

Com respeito aos efeitos fixos ou aleatórios, o teste de Hausman rejeitou a hipótese nos dois modelos, a um nível de significância de $1 \%$, sugerindo que o modelo de efeitos aleatórios é inconsistente. Portanto, as estimações definitivas para ambos os modelos utilizarão efeitos fixos.

Na tabela 4 estão relacionados os resultados das regressões que utilizaram como variável dependente o endividamento contábil, tanto com efeitos fixos, quanto com efeitos variáveis. Nos dois modelos, a estatística $\mathrm{F}$ mostra-se globalmente significativo a um nível de significância de 1\%. No modelo de efeitos fixos, percebe-se que as únicas variáveis estatisticamente significantes, foram a rentabilidade e o risco. As outras três variáveis não são significantes. Ainda nesse modelo, o $\mathrm{R}^{2}$ ajustado indica que o $31,98 \%$ das variações do endividamento contábil das empresas da amostra. Já no modelo de efeitos aleatórios, as variáveis estatisticamente significantes foram apenas a rentabilidade e o risco. Com respeito às dummies, cujos coeficientes foram omitidos, restaram significantes dos setores Alimentos e Bebidas, Comércio, Construção Civil, Minerais não Metálicos, Mineração, Siderúrgica e Metalúrgica, Veículos e Peças e Software e Dados. Quanto ao $\mathrm{R}^{2}$ ajustado, indica que o modelo é capaz de explicar 36,98\% das variações do endividamento contábil das empresas da amostra, no período estudado. 
Tabela 4: Modelo 1 - Variável Dependente: Endividamento Contábil (EndCont)

\begin{tabular}{l|rrrr|rrrr}
\hline & \multicolumn{5}{|c|}{ Efeitos Aleatórios $(*)$} & \multicolumn{5}{c}{ Efeitos Fixos } \\
\cline { 2 - 9 } & Estimate & Std.Error & \multicolumn{1}{c|}{ Test } & p-value & Estimate & Std.Error & Test & $p$-value \\
\hline (Intercept) & 0,29293 & 0,21099 & 1,4204 & 0,15549 & & & & \\
Rent & $-0,84316$ & 0,42762 & $-1,9706$ & 0,04877 & $-0,69663$ & 0,25413 & $-2,7412$ & 0,00612 \\
Risco & $-0,56715$ & 0,13451 & $-4,1821$ & $2,89 \mathrm{E}-05$ & $-0,83528$ & 0,22159 & $-3,7694$ & 0,00016 \\
Tamanho & 0,00490 & 0,01320 & 0,2830 & 0,77719 & 0,01947 & 0,05053 & 0,3853 & 0,70001 \\
Tang & 0,12028 & 0,11860 & 0,9974 & 0,31859 & 0,01928 & 0,13548 & 0,1424 & 0,88679 \\
OpCresc & 0,06437 & 0,05217 & 1,1573 & 0,24716 & 0,05267 & 0,03764 & 1,3992 & 0,16175 \\
\hline $\mathrm{R}^{2}$ & 0,39185 & & & & 0,44822 & & & \\
Adj.R ${ }^{2}$ & 0,36980 & & & & 0,31979 & & & \\
F-statistic: & 19,4199 & & & $2,21 \mathrm{E}-16$ & 85,2288 & & & $2,22 \mathrm{E}-16$ \\
\hline
\end{tabular}

(*) Estimativas para as variáveis dummies omitidas.

Fonte: Dados da pesquisa.

Quando se usa o endividamento a valor de mercado como variável dependente, conforme resultados apresentados na Tabela 5, também se conclui que as variáveis escolhidas exercem influência sobre a variável dependente, a um nível de significância de $1 \%$.

No modelo de efeitos fixos, a única variável não individualmente significante foi a tangibilidade dos ativos, o que é uma melhora em relação ao primeiro modelo. Entretanto, o $\mathrm{R}^{2}$ ajustado dessa regressão indica que apenas $26,74 \%$ das variações do endividamento a valor de mercado das empresas da amostra, no período, é explicada pelas variáveis independentes. Já no modelo com efeitos aleatórios, a variável tamanho saiu do rol de variáveis estatisticamente significantes. Com respeito às dummies, cujos coeficientes também foram omitidos, restaram significativos os setores Alimentos e Bebidas, Comércio, Minerais não Metálicos, Papel e Celulose, Petróleo e Gás, Veículos e Peças e Software e Dados. Quanto ao $\mathrm{R}^{2}$ ajustado, aqui levemente superior ao anterior, indica que as variáveis independentes explicam $38,15 \%$ das variações do endividamento a valor de mercado das empresas da amostra, no período estudado.

Tabela 5: Modelo 2 - Variável Dependente: Endividamento a Valor de Mercado (EndMer)

\begin{tabular}{l|rrrr|rrrr}
\hline & \multicolumn{3}{|c|}{ Efeitos Aleatórios (*) } & \multicolumn{4}{c}{ Efeitos Fixos } \\
\cline { 2 - 9 } & Estimate & Std.Error & Test & p-value & Estimate & Std.Error & Test & $p$-value \\
\hline (Intercept) & 0,44801 & 0,13656 & 2,74492 & 0,00597 & & & & \\
Rent & $-0,35924$ & 0,08756 & $-4,15614$ & $3,03 \mathrm{E}-05$ & $-0,32677$ & 0,10046 & $-3,2526$ & 0,00114 \\
Risco & $-0,17094$ & 0,13772 & $-1,43274$ & 0,21187 & $-0,24308$ & 0,11218 & $-2,1668$ & 0,03025 \\
Tamanho & 0,01856 & 0,00871 & 1,75516 & 0,07864 & 0,05405 & 0,01908 & 2,9886 & 0,00280 \\
Tang & $-0,01804$ & 0,04675 & $-0,38775$ & 0,69838 & $-0,09530$ & 0,07441 & $-1,2806$ & 0,21134 \\
OpCresc & $-0,13704$ & 0,01878 & $-6,50580$ & $7,73 \mathrm{E}-11$ & $-0,12771$ & 0,02069 & $-6,1694$ & $6,86 \mathrm{E}-10$ \\
\hline $\mathrm{R}^{2}$ & 0,38190 & & & & 0,36084 & & & \\
Adj.R & 0,38145 & & & & 0,26736 & & & \\
F-statistic: & 18,9283 & & & $2,21 \mathrm{E}-16$ & 61,1689 & & & $2,22 \mathrm{E}-16$ \\
\hline
\end{tabular}

(*) Estimativas para as variáveis dummies omitidas.

Fonte: Dados da pesquisa. 
Para a obtenção dos modelos finais, foi utilizada a regressão com efeitos fixos (assim como sugeriu o teste de Hausman), excluindo as variáveis que não se mostraram individualmente significantes. No modelo para endividamento contábil, cujo resultados são apresentados na Tabela 6 , foram utilizadas as variáveis risco e rentabilidade. Já no modelo para endividamento a valor de mercado, na Tabela 7 , restaram as variáveis independentes rentabilidade, risco, tamanho e oportunidades de crescimento. As dummies para setores da economia não aparecem no modelo final em razão de essas não se encaixarem no modelo com efeitos fixos. A estatística $\mathrm{F}$ mostrou que as variáveis em conjunto exercem influência sobre o nível de endividamento, em ambos os modelos.

Tabela 6: Modelo 1 Final - Variável Dependente: Endividamento Contábil (EndCont) com Efeitos Fixos

\begin{tabular}{lrrrr}
\hline & Estimate & Std. Error & Test & $p$-value \\
\hline Rent & $-0,66182$ & 0,05750 & $-12,378$ & $2,17 \mathrm{E}-16$ \\
Risco & $-0,84882$ & 0,08083 & $-12,172$ & $2,17 \mathrm{E}-16$ \\
\hline Soma dos quadrados totais & 9,62770 & & & \\
Soma dos quadrados dos resíduos & 5,58779 & & & \\
$\mathrm{R}^{2}$ & 0,41821 & & & \\
Adj. ${ }^{2}$ & 0,33031 & & & $2,23 \mathrm{E}-16$ \\
F-statistic: & 189,586 & & & \\
\hline
\end{tabular}

Fonte: Dados da pesquisa.

No primeiro modelo, com a exclusão das variáveis não significantes, o valor do $\mathrm{R}^{2}$ ajustado é de 0,330 . Com respeito aos sinais obtidos, foco desse estudo, ficou evidenciado que aumentos na rentabilidade, ou no risco, causam menor endividamento.

Tabela 7: Modelo 2 Final - Variável Dependente: Endividamento a Valor de Mercado (EndMer) com Efeitos Fixos

\begin{tabular}{lrrrr}
\hline & Estimate & Std. Error & Test & $p$-value \\
\hline Rent & $-0,33912$ & 0,04399 & $-7,1202$ & $3,46 \mathrm{E}-12$ \\
Risco & $-0,25503$ & 0,060162 & $-3,9346$ & $9,87 \mathrm{E}-05$ \\
Tamanho & 0,04985 & 0,01700 & 5,0752 & $5,09 \mathrm{E}-07$ \\
OpCresc & $-0,13075$ & 0,016531 & $-12,8849$ & $2,19 \mathrm{E}-16$ \\
\hline Soma dos quadrados totais & 4,8937 & & & \\
Soma dos quadrados dos resíduos & 3,1597 & & & \\
$\mathrm{R}^{2}$ & 0,3467 & & & \\
Adj. $\mathrm{R}^{2}$ & 0,2689 & & & \\
F-statistic: & 76,910 & & & $2,21 \mathrm{E}-16$ \\
\hline
\end{tabular}

Fonte: Dados da pesquisa.

Já o segundo modelo continuou com o $\mathrm{R}^{2}$ ajustado um pouco menor que o primeiro modelo, a pesar de conter mais variáveis independentes. Com respeito aos sinais dos coeficientes, ficou evidenciado que aumentos na rentabilidade, ou no risco, ou nas oportunidades de crescimento explicam menor endividamento; no caso do tamanho, empresas maiores tendem a ter maior endividamento. 
Com as regressões finais em mãos, pode-se proceder a análise da relação entre os coeficientes esperados e os coeficientes obtidos. O quadro 4 mostra a comparação entre esses coeficientes.

Quadro 4: Comparativo entre os sinais esperados e os sinais obtidos nessa pesquisa

\begin{tabular}{|l|c|c|c|}
\hline \multicolumn{1}{|c|}{ Determinantes } & \multicolumn{2}{|c|}{ Sinal Esperado } \\
(Pecking Order) & (Static Trade-off $)$ & Sinal Encontrado \\
\hline Rentabilidade & - & + & - \\
\hline Risco & - & - & - \\
\hline Tamanho & $n . p$. & + & + \\
\hline Tangibilidade & - & + & $-($ n.s. $)$ \\
\hline Oportunidades de crescimento & + & - & - \\
\hline
\end{tabular}

n.p.: não previsto; $n . s .:$ não estatisticamente significante.

Fonte: Dados da pesquisa.

Observa-se que, pela comparação com os resultados previstos pelas teorias, todas as variáveis apresentaram os resultados esperados, com exceção da tangibilidade dos ativos, que não apresentou significância.

A rentabilidade, nos dois modelos finais, apresentou coeficiente com sinal negativo, confirmando a hipótese levantada pela teoria do Pecking Order, de que empresas mais rentáveis deveriam ser menos endividadas. Portanto, empresas com maiores níveis de rentabilidade podem reter mais lucro, que pode ser utilizado em investimentos futuros, diminuindo sua necessidade de contração de dívidas.

Da mesma maneira que a rentabilidade, o risco também apresentou relação negativa com o endividamento, conforme previsto tanto pela teoria do Static Trade-off como pela do Pecking Order, empresas mais arriscadas têm maiores custos de falência, o que faz com que elas mantenham sua alavancagem financeira menor.

No modelo para o endividamento a valor e mercado, a variável tamanho apresentou coeficiente positivo, confirmando o que foi apontado pela teoria do Static Trade-off. Logo, empresas maiores possuem negócios mais diversificados, diminuindo seu custo de falência, o que as permite terem um maior nível de endividamento.

A tangibilidade se mostrou não-significante, indicando que esta variável não teve influencia nas decisões de endividamento das empresas da amostra.

As oportunidades de crescimento, por seu turno, se mostraram negativa e estatisticamente significante no modelo para o endividamento a valor de mercado, conforme previsão da teoria do Static Trade-off. Nesse caso, empresas com maiores oportunidades de crescimento têm seu valor determinado por expectativa de retorno futuro, além de seus ativos serem grande parte de intangíveis, o que faz com que seus custos de falência aumentem, diminuindo sua alavancagem financeira.

\section{CONCLUSÕES}

Este estudo se propôs a verificar o efeito de alguns determinantes na estrutura de capital de empresas brasileiras de capital aberto no período 2010-2017, um período de contração econômica. Os determinantes considerados foram aqueles sugeridos pelas teorias do Pecking Order e do Static Trade-off, e recorrentes em estudos empíricos recentes para períodos diversos, considerando empresas brasileiras de capital aberto. Para a análise, foi realizada uma análise estatística de dados em painel e modelos com efeitos fixos e com efeitos variáveis. Além disso, foram utilizadas duas proxies para o endividamento, a saber: endividamento contábil e 
endividamento a valor de mercado. Após os tratamentos estatísticos apropriados, verificou-se que o modelo mais representativo era aquele com efeitos fixos para ambas as proxies de endividamento.

Analisando o modelo para endividamento contábil, os resultados apurados apontaram as variáveis explicativas rentabilidade e risco como estatisticamente significantes. O coeficiente negativo para a rentabilidade está de acordo com o proposto pela teoria do Pecking Order. O coeficiente negativo para o risco está de acordo com o previsto por ambas as teorias, Pecking Order e Static Trade-off.

Com respeito ao modelo para endividamento a valor de mercado, os resultados apurados indicam as variáveis rentabilidade, risco, tamanho e oportunidades de crescimento como significativas. O coeficiente negativo para a rentabilidade está em conformidade com o previsto pelo Pecking Order. Os demais coeficientes estão de acordo com o previsto pelo Static Trade-off.

Destaque-se que a variável que mede a proporção de ativos fixos no ativo total das empresas da amostra, a tangibilidade, não se mostrou significativa para o período es dades em questão, para nenhuma das duas proxies de endividamento.

Com respeito aos setores em que se inserem cada empresa da amostra, obteve-se evidência de estrutura de capital algo distinta da média em alguns casos. Contudo, tal evidência é pouco significativa dada não só a pequena representatividade de alguns, mas o fato de que o teste de Hausman concluiu pela inexistência de efeitos aleatórios. A esse respeito, portanto, estudos adicionais e setores-específicos devem ser realizados.

Apesar da explicação satisfatória da estrutura de capital com as variáveis relacionadas, os modelos apresentaram um valor do $\mathrm{R}^{2}$ ajustado pequeno, sugerindo que existem outras variáveis que influenciaram o nível de endividamento das empresas da amostra no período, e que não foram explicitados neste estudo. Por fim, cabe ressaltar que os resultados obtidos são específicos para o período analisado, com aplicabilidade limitada para previsões acerca de estrutura de capital das empresas brasileiras de capital aberto no futuro. Tal conclusão é suportada pelas proposições teóricas distintas, como pelos estudos empíricos anteriormente realizados para empresas brasileiras e períodos distintos.

Por fim, como sugestão de pesquisa futura, identifica-se espaço para uma meta- análise que evidencie quais determinantes são mais relevantes, e quais são menos, para a decisão de endividamento de empresas de capital aberto para distintas conjunturas macroeconômicas.

\section{REFERÊNCIAS}

ALBANEZ, T.; VALLE, M.; CORRAR, L. Fatores institucionais e assimetria informacional: influência na estrutura de capital de empresas brasileiras. Revista de Administração Mackenzie, v.13, n.2, p. 76-105, 2012.

ANDERSEN, T. J. Risk management, capital structure, and performance: A real options perspective. Global Business e Economics Anthology, v.24, n.2, p. 1-19, 2005.

ANGONESE, R.; SANTOS, P.; LAVARDA, C. Valor econômico agregado e estrutura de capital em empresas do IBRX 100. ConTexto, v.11, n.20, p. 7-17, 2011.

BASKIN, J. An empirical investigation of the pecking order hypothesis. Financial Management, v.18, n. 1, p. 26-35, 1989. 
BASTOS, D. D.; NAKAMURA, W. T. Determinantes da estrutura de capital das companhias abertas no Brasil, México e Chile no período 2001-2006. Revista Contabilidade \& Finanças, v.20, n. 50, p. 75-94, 2009.

BAXTER, N. D. Leverage, risk of ruin and the cost of capital. The Journal of Finance, v.22, n. 3, p. 395-403, 1967.

BREALEY, R.; LELAND, H. E.; PYLE, D. H. Informational asymmetries, financial structure, and financial intermediation. The Journal of Finance, v.32, n. 2, p. 371-387, 1977.

BRITO, G. A.; CORRAR, L. J.; BATISTELLA, F. D. Fatores determinantes da estrutura de capital das maiores empresas que atuam no Brasil. Revista Contabilidade \& Finanças, v.18, n. 43, p. 9-19, 2007.

BRUNOZI, M.; GNÇALVES, R. ARANTES; R. E BRUNOZI Jr., A. Indicadores econômico financeiros e os determinantes da estrutura de capital das empresas do setor de serviços: uma análise de dados em painel. Revista Ambiente Contábil, v.8, n. 2, p. 110-135, 2016.

CORREA, C.; BASSO, L.; NAKAMURA, W. A estrutura de capital das maiores empresas brasileiras. Revista de Administração Mackenzie, v.14, n. 4, p. 106-133, 2013.

CRISTÓFAlO, R. G.; AKAKI, A. S.; ABE, T. C.; MORANO, R. S.; MIRAGLIA, S. K. Sustentabilidade e o mercado financeiro: estudo do desempenho de empresas que compõem o índice de sustentabilidade empresarial (ISE). Revista de Gestão, v.23, n. 4, p. 286-297, 2016.

DEANGELO, H.; MASULIS, R. W. Optimal capital structure under corporate and personal taxation. Journal of Financial Economics, v.8, n. 1, p. 3-29, 1980.

FAMÁ, R.; GRAVA, J. W. Teoria da estrutura de capital - as discussões persistem. Caderno de Pesquisas em Administração, v.1, n. 11, p. 27-36, 2000.

FAVATO, V. Determinantes da estrutura de capital na América Latina e nos Estados Unidos. 2007. Dissertação (Mestrado) - Universidade Federal de Uberlândia, Uberlândia, Minas Gerais, 2007.

FAVATO, V.; ROGERS, P. Estrutura de capital na América Latina e nos Estados Unidos: Uma análise de seus determinantes e efeito dos sistemas de financiamento. Gestão \& Regionalidade, v.24, n. 71, p. 31-43, 2008.

FERREIRA, L. D. S.; BRASIL, H. (1997). Estrutura de capital: Um teste preliminar da pecking order hypothesis. Anais... In: Encontro Nacional da Associação Nacional de Pós-Graduação e Pesquisa em Administração, Rio de Janeiro, 1997. Rio de Janeiro, RJ: ANPAD.

GOMES, G. L. Determinantes da estrutura de capitais das empresas brasileiras com ações negociadas em bolsa de valores. 1999. Dissertação (Mestrado) - Universidade Federal do Rio de Janeiro, Rio de Janeiro, Rio de Janeiro, 1999.

GOMES, G. L.; LEAL, R. P. C. L. Determinantes da estrutura de capitais das empresas brasileiras com ações negociadas em bolsas de valores. São Paulo: Atlas, 2001. 
GONÇALVES, D; BISPO, O. Análise dos fatores determinantes da estrutura de capital de companhias de construção civil inseridas no segmento Bovespa. Revista de Contabilidade e Controladoria, v.4, n. 1, p. 110-130, 2012.

HEINKEL, R.; ZECHNER, J. The Role of Debt and Perferred Stock as a Solution to Adverse Investment Incentives. Journal of Financial and Quantitative Analysis, v.25, n. 1, p. 1-24, 1990.

ISLAM, S. Z.; KHANDAKER, S. Firm leverage decisions: does industry matter? The North American Journal of Economics and Finance, v.31, 94-107, 2015.

JENSEN, M. C.; MECKLING, W. H. Theory of the firm: Managerial behavior, agency costs and ownership structure. Journal of Financial Economics, v.3, n. 4, p. 305-360, 1976.

KIRCH, G. Determinantes da estrutura de capital das empresas brasileiras de capital aberto. ConTexto, v.8, n. 13, p. 1-21, 2008.

LOCATELLI, R.; NASSER, J.; MESQUITA, J. Fatores determinantes da estrutura de capital no agronegócio: o caso das empresas brasileiras. Organizações Rurais \& Agroindustriais, v.17, n. 1, p. 72-86, 2015.

MACHADO, L. K.; PRADO, J. W.; CARVALHO VIEIRA, K.; ANTONIALLI, L. M.; DOS SANTOS, A. C. A relevância da estrutura de capital no desempenho das firmas: uma análise multivariada das empresas brasileiras de capital aberto. Revista de Educação e Pesquisa em Contabilidade, v.9, n. 4, p. 397-414, 2015.

MARTINS, H.; TERRA, P. Determinantes Nacionais e Setoriais da Estrutura de Capital na América Latina. Revista de Administração Contemporânea, 18, n. 5, p. 577-597, 2014.

MILLER, M. H. Debt and taxes. The Journal of Finance, v.32, n. 2, p. 261-275, 1977.

MODIGLIANI, F.; MILLER, M. H. The cost of capital, corporation finance and the theory of investment. The American Economic Review, v.48, n. 3, p. 261-297, 1958.

MODIGLIANI, F.; MILlER, M. H. Corporate income taxes and the cost of capital: A correction. The American Economic Review, v.53, n. 3, p. 433-443, 1963.

MORAES, E.G. Determinantes da estrutura de capital das empresas listadas na Bovespa. 2005. Dissertação (Mestrado) - Universidade Federal do Rio Grande do Sul, Porto Alegre, Rio Grande do Sul, 2005.

MYERS, S. C. The capital structure puzzle. The Journal of Finance, v.39, n. 3, p. 574-592, 1984.

MYERS, S. C.; MAJLUF, N. S. Corporate financing and investment decisions when firms have information that investors do not have. Journal of Financial Economics, v.13, n. 2, p. 187221, 1984.

NAKAMURA, W. T.; MARTIN, D. M.; FORTE, D.; CARVALHO, A.; DA COSTA, A. F.; DO AMARAL, A. C. Determinantes de estrutura de capital no mercado brasileiro: análise de regressão com painel de dados no período 1999-2003. Revista Contabilidade \& Finanças, v.18, n. 44, p. 72-85, 2007.

Revista Ambiente Contábil - ISSN 2176-9036 - UFRN - Natal-RN. v. 10. n. 2, p. 364 - 383, jul./dez. 2018. 
NAKAMURA, W. T.; MARTIN, D. M. L.; KIMURA, H. Indicadores contábeis como determinantes do endividamento das empresas brasileiras. In: Encontro Nacional da Associação Nacional de Pós-Graduação e Pesquisa em Administração, Anais..., Curitiba, Paraná, 2004.

NARAYANAN, M. P. Debt versus equity under asymmetric information. Journal of Financial and Quantitative Analysis, v.23, n. 1, p. 39-51, 1988.

PEROBELLI, F. O.; FAMÁ, R. Determinantes da estrutura de capital: Aplicação a empresas de capital aberto brasileiras. Revista de Administração da USP, v.37, n. 3, p. 33-46, 2002.

POHLMANN, M. C.; IUDÍCIBUS, S. Relação entre a tributação do lucro e a estrutura de capital das grandes empresas no Brasil. Revista Contabilidade \& Finanças, v.21, n. 53, p. 1$25,2010$.

RAJAN, R. G., E ZINGALES, L. What do we know about capital structure? Some evidence from international data. The Journal of Finance, v.50, n. 5, p. 1421-1460, 1995.

ROSS, S. A. The determination of financial structure: The incentive-signalling approach. The Bell Journal of Economics, v.8, n. 1, p. 23-40, 1977. 